In other directions wireless telegraphy is showing that it has won the right to consideration as a thoroughly practical means of communication. The extract from a letter from the "wireless" correspondent of the Times in the Far East which was printed in last week's NATURE shows to how great an extent it is being used in the Russo-Japanese war. The letter also shows that, whatever may be said to the contrary, syntonisation in the true sense is still a problem awaiting solution. The most that can be done at present seems to amount to this: a receiving station can be syntonised sufficiently well to enable it to pick up messages from a particular transmitting station in preference to, or with greater ease than, those from any other, and thus it may be enabled to work over greater ranges. It does not, however, seem in the least possible so to tune the transmitter that interception of messages is impossible, nor does it seem likely that this will ever be accomplished until experimenters have succeeded in producing continuous trains of undamped oscillations, a direction in which many are working. It is noteworthy that Dr. de Forest recently expressed the opinion that without this syntonisation is only partially possible; in this limited sense we believe all systems are making use of the principle with more or less success. The system designed by Dr. de Forest appears from many accounts to be the most efficient of those at work at the seat of war, as it has already been one of the most successful of those tried in America. The lengthy wireless messages transmitted with marked regularity in trying circumstances from the Haimun to the Times afford evidence of this, and it is noteworthy also that a speed of about thirty words a minute seems to be easily attained, which is a high speed for wireless telegraphy. The comparisons which the Times correspondent makes between the working of his system and that on the British warships at Wei-hai-wei, though much to the detriment of the latter, are hardly fair to the Marconi system, as the naval installations are not of the latest date.

As to the prospect of attaining thorough syntonisation, it is to be noted that Dr. de Forest is working on the lines of producing continuous oscillations on the principle of 'Duddell's singing arc, a method which, we pointed out in Nature (vol. Ixviii. p. 248), seemed the most promising. Others, we believe, are also working on the same lines. It is noteworthy also that much progress has been made on the scientific side, and that we are in a better position now to make quantitative measurements of the enefgy transmitted and received. In this connection also Mr. Duddell has contributed towards our advance; he recently exhibited before the Physical Society an instrument (which we hope to describe on another occasion) which gave considerable deflections with the currents reccived in the aerrial wires. As this affords the first means we have of accurately measuring these currents, it may prove of great value in the development' of the science.

\section{Maurice Solomon.}

\section{REPORT OF THE METEOROLOGICAL GRANT} COMMITTEE.

I N December, 1902, a committee was appointed by the

Treasury "to inquire and report as to the administration by the Meteorological Council of the existing parliamentary grant, and as to whether any changes in its apportionment are desirable in the interest of meteorological science, and to make any further recommend. ations which may occur to them with a view to increasing the utility of that grant." The committee was composed of Sir Herbert E. Maxwell, Bart., M.P. (chairman), Mr.
J. A. Dewar, M.P., Sir W. de W. Abney, K.C.B., F.R.S., Sir F. Hopwood, K.C.B., C.M.G., Board of Trade, Sir T. H. Elliotı, K.C.B., Board of Agriculture, Mr. 'T. L. Heath, Treasury, Dr. R. T. Glazebrook, F.R.S., and Prof. Joseph Larmor, F.R.S.

The report of the committee has just been published as a Blue-book ( $\mathrm{Cd}$. 2123 , price $2 \frac{1}{2} d$.), and a summary of some of the points of scientific interest in it is subjoined.

\section{SCIENTIFIC RESEARCH.}

The committee of 1877 recommended that "the counci should be at liberty to appropriate a part of their annual grant to the purposes of any special researches which they may think important, and in such cases it should rest with them to select the investigators and fix the remuneration."

The council, as might be expected of a body appointed by, and reporting annually to, the Royal Society, has never lost sight of this part of its functions; but the expansion of the routine work of the office, including therein the receipt, discussion and reduction of observations, the preparation and issue of forecasts and warnings, the supply of instruments and the annual inspection of observatories, \&c., has absorbed nearly the whole of the grant, leaving a comparatively trifling sum- $7 \mathrm{ool}$. to $800 \mathrm{l}$. - to be devoted to meteorological research. The council has made a strong representation that, for the effective performance of this part of its duties, the staff requires strengthening by the addition of "a few assistants specially qualified by a knowledge of mathematics and physics for undertaking the investigation of such questions as are contemplated." The additional annual cost of three such assistants, with the incidental expenses, was estimated at 2250 . It appears from the evidence that it would be desirable for the council to have access to a meteorological laboratory properly equipped, which would serve as one of the first-order observing stations.

We believe that the time has arrived when one of two alternatives must be taken, viz. either to provide the Meteorological Office with the additional funds necessary for the effective prosecution of independent and cooperative research, or practically to confine the functions of the Meteorological Office to the ordinary routine work. In this latter case it would be necessary to rely upon members of the council who are appointed by the Royal Society to keep abreast of the advance in meteorology which may be achieved by British and foreign scientific societies and by the Governments of foreign countries independently of the office.

We do not believe that a middle course can be pursued with any advantage. The present grant is little more than enough to maintain the office, the five observatories depending thereon, and the library, and to provide for the superannuation of the staff. It would be better to circumscribe the operations of the council to routine than to expect them to undertake investigations for which they have not adequate means.

An example of the difficulty arising under present conditions may be cited in the invitation forwarded by the Foreign Office to the council in 1902 to join in an international scheme for investigating the upper atmosphere by means of kites and balloons. The invitation had to be declined for want of the requisite $500 l$. a year.

It is clear that, from the first, it was intended that the directors of the Meteorological Office should be chosen with a view to their capacity for directing experiment and research; otherwise their appointment would not have been committed to the Roval Society. On the other hand, we perceive strong objections to granting money for scientific research in meteorology, except on the direct responsibility of a Minister of the Crown. This brings us back to the repeated recommendation of the Royal Society that the Meteorological Office should form part of one of the Government departments - a recommendation which we have included among those now submitted to your lordships.

It appears that the present constitution of the Meteorological Office was never regarded by the Royal Society as a permanent one, but as " a temporary measure till some other organisation should be carried out." We regard this as a favourable opportunity for placing the Meteorological Office upon a permanent footing.

No. I808, vOL. 70] 
Recommendations.

We are of opinion that the registration of the Meteorological Office as a company under the Joint Stock Companies' Acts should be cancelled, that the company should be wound up, and the office reconstituted as a department under the control of the Board of Agriculture and Fisheries.

The necessity for a council of seven having thus been got rid of, we recommend that the office be placed under the control of a man of science as director of meteorology, appointed after consultation with the Royal Society, but responsible to the Board of Agriculture and Fisheries, and making his annual report to that department. We recommend also the appointment of an advisory board, consisting of the hydrographer to the Admiralty, a representative of the Board of Trade, and one of the Board of Agriculture and Fisheries, and two members nominated by the Royal Society. The functions of the advisory board should be consultative only, the director being responsible to the Board of Agriculture and Fisheries for administration.

We recommend also that a second officer be appointed to act as scientific assistant to the director, to assist him in the general management of the office and in the discussion of such scientific problems as may arise.

The mean annual cost of this arrangement, as compared with that for the present council, we estimate thus:-

\section{Present Arrangement}

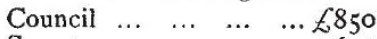

Secretary

$$
\cdots \quad \cdots \quad \ldots \quad 625
$$

Proposed Arrangement

Director $£ 800$ rising to $£ 1000$ Scientific Assistant ... 450

$$
\text { Mean ... }
$$

The fixed parliamentary grant of $15,300 l$. should be transferred to the vote for the Board of Agriculture and Fisheries.

Under such an arrangement the anomaly would cease of what is practically a department of the public service though nominally a joint stock company, paying for postal and telegraph services money out of its fixed income. The charge for these services would not appear in the estimate, though undoubtedly the revenue would be the loser by the amount now repaid out of the parliamentary grant. The director of meteorology would not then feel, as the council now does, that the more complete and rapid the distribution of forecasts and warnings is made, the less money remains for scientific research and for overtaking arrears in the statistical work of the department.

Further, we judge it important that the Post Office should make arrangements at the twenty-seven reporting stations in the United Kingdom for the transmission of daily telegraphic reports one hour earlier than the present one of 8.15 to 8.30 a.m., and that storm warnings should, if practicable, have priority over all private messages at all hours.

We would direct attention to the expediency of testing the efficacy of wireless telegraphy in providing advance news of weather in the Atlantic. Such news would incalculably strengthen the forecast and warning service, and might, we believe, be obtained regularly over an experimental period by cooperation either with the Admiralty, the ocean steamship companies, or both. We would urge that no unnecessary delay should take place in organising this experiment.

We recommend that in future the cost of instruments supplied to His Majesty's ships be borne upon the Navy votes, except where such instruments are intended for use in research or observation specially called for by the director of meteorology.

We consider that the premises now rented by the council are neither suitable in character nor adequate in space for the present requirements of the office, and that others should be provided wherein the staff might perform their duties under more favourable hygienic conditions, and necessary accommodation for the rapidly growing library might be secured.

We recommend that the staff employed in the library, the statistical branch and observatory branch, should be augmented. The steps necessary to give effect to this and the preceding recommendation can best be determined when the future of the office has been decided upon.

We have carefully considered the effect of our recommend- ations upon the apportionment of the present grant of $15,300 l$.

Our recommendations would involve a net increase of 449l. Another effect would be to reduce the Post Office revenue by the sum of about $2000 l$, and to transfer to Navy votes, for instruments supplied to the Royal Navy, about $500 l$.

In default of an increase to the grant, the small increased expenditure which we have recommended would have either to be postponed or to be met from economies on other branches of the work of the office.

Wè have not included in the figures above given any increase in the average amount of the grant allocated to scientific research, nor have we found means of providing for increased telegraph expenditure which the adoption of the recommendations as to the transmission of earlier daily telegtaphic reports, and of storm warnings, will very probably entail on the Post Office.

The evidence before us has shown conclusively the importance of further scientific research, for which we trust that funds may be forthcoming in the near future.

In mincrity reports Sir Herbert Maxwell and Sir William Abney express disagreement with that part of the report which deals with the action of the Meteorological Counci in deciding to discontinue the annual payment to Fort William Observatory, involving the abandonment of the observatory on Ben Nevis.

Mr. Dewar objects to the action taken by the council in connection with superannuation; and Sir Francis Hopwood and $\mathrm{Mr}$. 'T. L. Heath are unable to concur in the recommendations made by a majority of the committee $(a)$ in so far as they would necessarily involve an increase in the annual grant, and $(b)$ in so far as they relate to the transfer of this grant from the vote for scientific investigations, \&c. to that of the Board of Agriculture and Fisheries.

\section{NOTES.}

THE following announcement of a munificent gift for scientific research appeared in Monday's Times:-Mrs. Percy Sladen, of Northbrook Park, Devonshire, in the desire to perpetuate the memory of her late husband, Mr. W. P. Sladen, sometime secretary and vice-president of the Linnean Society, has undertaken to devote the sum of $20,000 l$. to the promotion of scientific research, particularly in the subjects in which he was chiefly interested. She proposes to assign this sum under the name of the Percy Sladen memorial fund to certain trustees, in the first place of her own appointment, who are directed to employ the income arising therefrom, in their uncontrolled discretion, to " any research or investigation in natural science, and more especially in the sciences of zoology, geology, and anthropology." They are also empowered, if they think fit, to accumulate the income for the purpose of fitting out, or assisting to fit out, any expedition designed to further such research. The following gentlemen, whom Mrs. Sladen has requested to be the first trustees, have consented to serve :- her brother, Dr. Tempest Anderson, of York; Mr. Bailey Saunders, Mr. Henry Bury, Dr. Henry Woodward, F.R.S. Prof. Howes, F.R.S., and Prof. Herdman, F.R.S. On the occurrence of any vacancy among these trustees, Mrs. Sladen reserves to herself the right to nominate their successors; but by the deed of endowment it is provided that eventually five trustees shall be severally nominated for a period of five years each by the following bodies in rotation, so far as they may have signified their acceptance of the power of appointment:-the Royal Society, the Linnean Society, the trustees of the British Museum, and the Universities of Oxford and Cambridge.

As a result of a petition in 1902 from the Johannesburg branch of the South African Association for the Advancement of Science to the Governor of the colony, a Govern-

No. I 808 , voL. 70] 